\title{
PLANIFICACIÓN DE LAS ÁREAS VERDES PERIURBANAS A TRAVÉS DE LA SALVAGUARDA Y RECUPERACIÓN DE ENCLAVES DE VALOR ECOLÓGICO Y PAISAJÍSTICO BAJO RIESGO. EL CASO DE LA CIUDAD DE AGUACHICA (COLOMBIA)*
}

Carlos Humberto Gómez Arciniegas, Arquitecto, MSc. Phd.***

Universidad Santo Tomás, Colombia

Daniel Reinaldo Urbina Rojas, Arquitecto****

Carlos Andrés Zuleta Torrado, Arquitecto******

Recibido: 29 enero 2013

Aprobado: 08 abril 2013

Paisaje Aguachica desde el Bosque del Agüil Fuente: Archivo de los autores

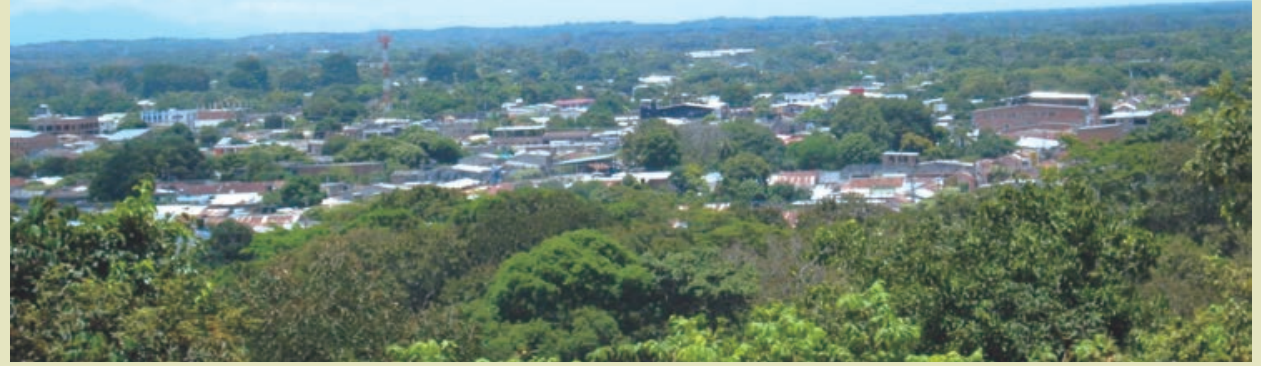

\section{RESUMEN}

* Artículo desarrollado a partir del proyecto de grado en modalidad de investigación: La articulación del bosque del Agüil dentro de un corredor ecológico periurbano para Aguachica (Cesar), incluido dentro de la Línea de Investigación: Planificación y Gestión del Territorio de la Facultad de Arquitectura de la Universidad Santo Tomás, Bucaramanga, Colombia.

** Arquitecto egresado de la Universidad Santo Tomás de Bucaramanga (Colombia) con MSc de la Lancaster University (Inglaterra) y $\mathrm{PhD}$ del Politécnico di Milano (Italia). Actualmente se de-

Con el paso del tiempo y el avance de la tecnología, las ciudades crecen de manera abrupta, consumen indiscriminadamente áreas que aún poseen las características necesarias para contribuir a su desarrollo sostenible. Este trabajo de investigación parte de un interés particular por las áreas periurbanas de las ciudades, territorios que se han visto afectados por el fenómeno de la expansión urbana descontrolada y que ha arrojado como balance poco alentador la disminución o incluso desaparición de las áreas verdes de margen, escenarios fundamentales para la protección del medio ambiente, de la biodiversidad y el mejoramiento del paisaje urbano. En consecuencia, el presente trabajo toma como punto de partida la preocupación por rescatar los márgenes de la ciudad de Aguachica (Departamento del Cesar), con la finalidad de brindarle al municipio una respuesta de múltiple valencia a las situaciones de riesgo que comprometen el verde urbano y los espacios naturales de este territorio. Entra en juego, como eslabón fundamental de la investigación el “Bosque del Agüil”, una joya ecológica localizada en el perímetro municipal y que posee indiscutiblemente las características necesarias para funcionar como primer elemento constitutivo de una serie de polos verdes que entrarían a hacer parte imprescindible de un corredor ecológico que abrace toda la ciudad. Se busca, por tanto, alcanzar este objetivo mediante el desarrollo de cuatro fases que ven un inicio con una lectura del territorio, prosigue con un análisis y diagnóstico de la situación existente, la cual una vez confrontada con una serie de tipologías y normativas identificadas en diferentes ámbitos, cimentarán la formulación de unos lineamientos estratégicos de planificación que permitan postular un corredor verde que bien podría rodear el municipio de Aguachica. En consecuencia, el Bosque del Agüil participaría como polo inicial y laboratorio experimental destinado a una nueva cultura de la planificación de las áreas verdes periurbanas bajo riesgo, merecedoras de su rescate por la importancia de su biodiversidad y por ser parte indivisible y necesaria de un hábitat ideal para vivir.

\section{PALABRAS CLAVE}

Enclaves, Ecológico, Corredor, Paisaje urbano, Periurbano 


\section{THE PLANNING OF PERIURBAN GREEN AREAS THROUGHOUT THE SAFEGUARDING AND RECOVERY OF ECOLOGICAL AND SCENIC VALUE SITES AT RISK. THE CASE OF THE CITY OF AGUACHICA (COLOMBIA)}

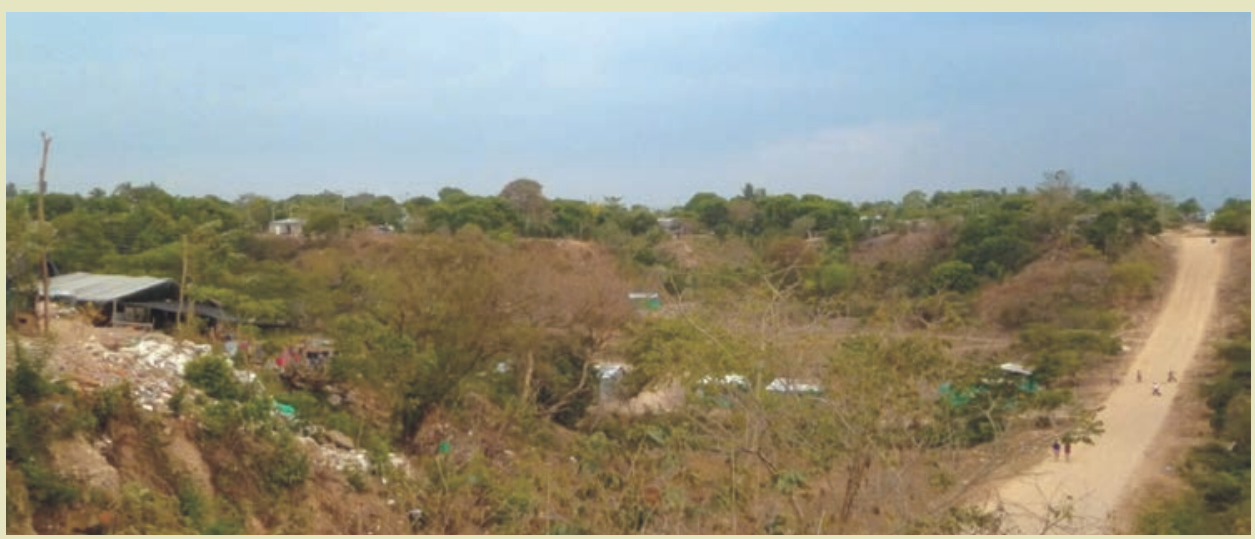

Bosque La Libertad

Fuente: Archivo de los autores

\begin{abstract}
With the passage of time and advancement of technology, cities grow abruptly, indiscriminately consume areas still possess the necessary characteristics to contribute to sustainable development. This research of particular interest in periurban areas of cities, territories that have been affected by the phenomenon of urban sprawl and has thrown as bleak balance the decrease or even disappearance of the green areas of margin, basic scenarios for environmental protection, biodiversity and improvement of the urban landscape. Thus, this paper takes as its starting point the concern to rescue the city margins Aguachica (Department of Cesar), in order to give the municipality a multiple response valence risk situations involving the urban green and natural areas of this territory. Comes into play, as a fundamental link of the investigation "the Agüil Forest" (Bosque del Agüil), an ecological jewel city located on the urban fringes which arguably has the features needed to run as the first element of a series of green poles that would come to be part must of an ecological corridor that embraces the entire city. The aim is therefore to achieve this through the development of four phases which are the beginning with a reading of the territory, continues with an analysis and diagnosis of the existing situation, which once confronted with a series of typologies and regulations identified in different areas will cement the formulation of a strategic planning guidelines that allow postulate a green corridor that could well encircle the city of Aguachica and in which the Agüil Forest be an initial pole and participate as experimental laboratory, aimed at a new cultural planning culture of periurban green areas at risk which deserve to be rescued by the importance of biodiversity and to be indivisible and necessary part of an ideal habitat to live.
\end{abstract}

sempeña como docente investigador de la Universidad Santo Tomás de Bucaramanga y es el director del proyecto de creación de la Maestría en Ordenamiento Territorial MOT de la Facultad de Arquitectura de la Universidad Santo Tomás de Bucaramanga.

*** Arquitecto egresado de la Universidad Santo Tomás de Bucaramanga (Colombia)

***** Arquitecto egresado de la Universidad Santo Tomás de Bucaramanga (Colombia)

carlos.gomez@polimi.it canzuleta@hotmail.com

\section{KEYWORDS}

Urbanlandscape, Peri-urban, Ecological corridor. 


\section{INTRODUCCIÓN}

El crecimiento demográfico, la despoblación del sector rural, los desequilibrios socioeconómicos y la expansión urbana son fenómenos que se han convertido en un común denominador para la mayoría de las ciudades. Las causas y los efectos inherentes a estos problemas son de diversa índole, afectan el escenario habitado, el paisaje natural y, de una u otra forma, involucran al elemento humano, principal escultor de estos escenarios. Entre estas situaciones negativas, fruto del acelerado proceso de urbanización que afrontan muchas ciudades colombianas, sobresale el déficit de espacio público y en particular el de áreas verdes. En efecto, las ciudades se ven inmersas en la constante "lava volcánica" de la expansión urbana que no da cabida a espacios aptos para el desarrollo de actividades al aire libre, sean activas o pasivas, o simplemente para un simple pero necesario contacto del hombre con la naturaleza.

Paradójicamente, el hombre parece preocuparse más por el hecho de transformar los espacios verdes en un "territorio de cemento" que por los efectos que esta tendencia implica: sobrepoblación, polución descontrolada, sobrecalentamiento climático, problemáticas sociales y caos infraestructurales, entre otros. En fin, un panorama incierto que invita a reflexionar cuán vital es para el desarrollo de una ciudad y de la sociedad que la habita, la inclusión de espacios naturales que funcionen como pulmones, micro climas, o áreas de alivio entre el tráfico y los edificios cotidianos. Escenarios propicios para alcanzar este ideal son las áreas periurbanas, zonas al margen de las ciudades que esbozan un tercer territorio, punto de contacto entre lo rural y lo urbano, una frontera que puede y debe ser utilizada para detener el crecimiento descontrolado de las ciudades y proporcionar espacios naturales para toda la población.

En razón de lo expuesto, se puede entrever el punto de partida de la presente investigación y los elementos concomitantes que coadyuvaron a la selección y definición final del tema de investigación, vislumbrado previamente a partir de reflexiones que llevaban a comparar casos de éxito en ámbito nacional e internacional con la realidad de un territorio seleccionado por un interés personal de los autores: Los márgenes periurbanos de Aguachica, ciudad ubicada en la región Caribe de Colombia, al sur del Departamento del Cesar, entre la cordillera oriental y el Valle del Río Magdalena, a una distancia de 30I km de Valledupar, la capital de dicho Departamento (ver Figura I).

Figura I. Ubicación de Aguachica, Departamento del Cesar. Fuente: Google Earth

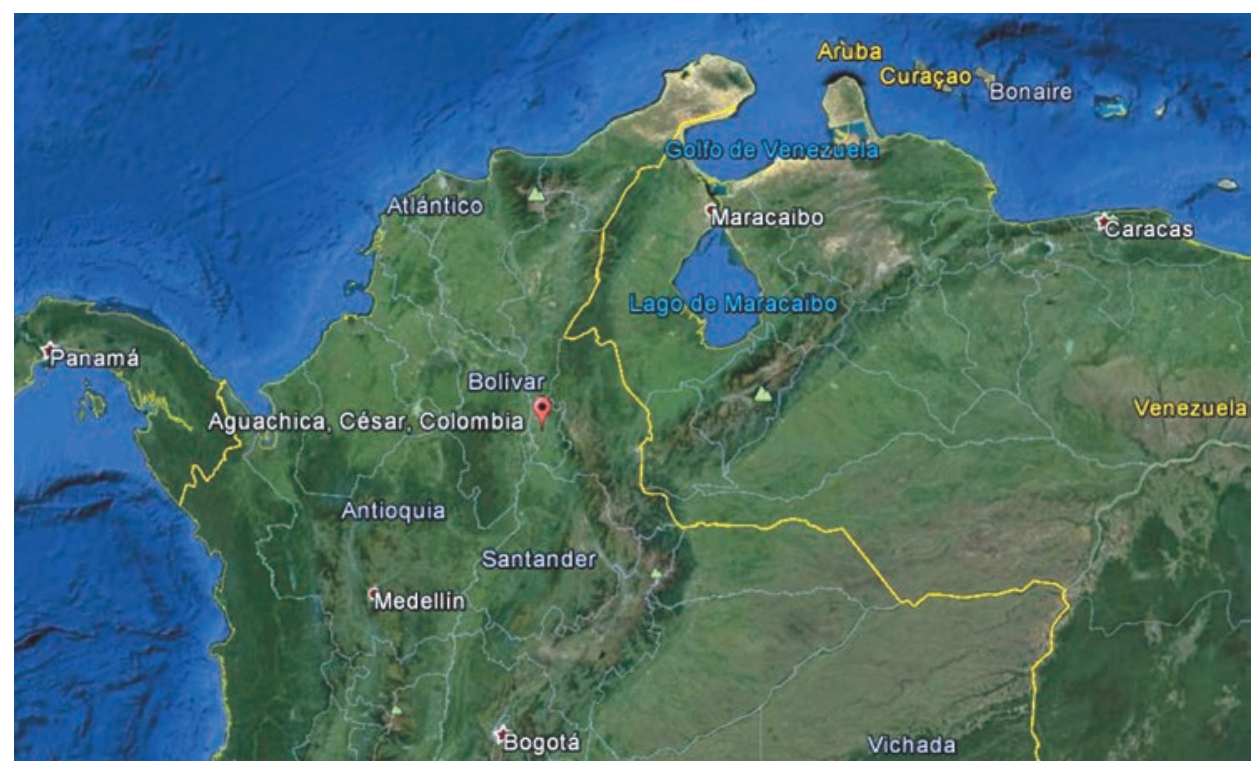


Así bien, para consolidar el problema de investigación se realizó un acercamiento al territorio con el fin estudiar sus problemáticas y potencialidades para vislumbrar un posible aporte investigativo que respondiese a la problemática ambiental que actualmente afronta la ciudad. De esta manera, se identifican problemáticas relacionadas con un alto déficit de verde urbano y con el deterioro del verde aún presente en los márgenes de la ciudad, áreas con diferentes características e interesantes particularidades. Sobresale entre ellas el parque denominado Bosque de El Agüil, situado en el margen oriental del casco urbano y el cual es en realidad un bosque periurbano dotado de una gran biodiversidad, donde surgen pequeñas corrientes de agua de gran pureza que se deslizan por algunos sectores de la ciudad compacta pero donde, lamentablemente, se contaminan y se deterioran.

También se identifican otros problemas como la intoxicación de las cuencas urbanas en detrimento de la salud de la población, de la flora y de la fauna vernácula. Más adelante, se pudo determinar, mediante sucesivas visitas de campo y la información proporcionada por los entes administrativos de Aguachica y el departamento del Cesar, cómo el crecimiento descontrolado de la ciudad no solamente ha impactado negativamente el área de El Agüil, sino que ha incidido sobre la mayor parte del territorio periurbano, afectado en gran parte por el deseo de urbanizar, formal o clandestinamente estos espacios vitales para el desarrollo sostenible de la ciudad. Se detectan situaciones análogas en la casi totalidad del "marco periurbano" de la ciudad: un paisaje subyugado por la entronización irracional, deteriorado ambiental, paisajísticamente $y$ afligido por problemas de salubridad.

Por consiguiente, se opta por tomar el Bosque del Agüil como estudio de caso piloto y punto de partida para la lectura del territorio, gracias a sus características y a su posición estratégica que, confrontadas con el déficit de verde urbano y los problemas emergentes del territorio periurbano, cimentaron la formulación de los objetivos. En términos metodológicos, se acude a un estudio de tipo exploratorio y descriptivo aplicado sobre el territorio que sustenta el diagnóstico y posteriormente la verificación de las hipótesis y los eventuales resultados de la investigación. Así pues, se propone un método de investigación articulado en cuatro fases, que incluyen la observación, la deducción y el análisis, todo ello con respeto del rigor de la investigación para establecer una secuencia lógica dirigida de mayor conocimiento sobre el tema en cuestión(Méndez, 2002).

La primera parte de la investigación se enfocó en la lectura del territorio, particularmente en la zona periurbana para identificar la disponibilidad de verde urbano y después concentrarse en el Bosque de El Agüil como estudio primario de caso. Se continuó con el análisis y diagnóstico de los resultados obtenidos en la primera fase donde se procura, mediante el uso de herramientas de planificación, determinar la potencialidad y debilidades del territorio para esbozar inicialmente las primeras estrategias, susceptibles de aplicación. Luego se realizó el estudio de caso o confrontación tipológica, con el fin de tener evidencia de proyectos con características similares en otros contextos y observar qué afectaciones tuvieron estos y sobre la sociedad y qué tan viable sería la realización de una campaña de estas magnitudes en Aguachica. La fase final vela por retroalimentar la información, contrastar y verificar las hipótesis para generar los lineamientos proyectuales necesarios para la realización del corredor ecológico en Aguachica, tomando como polo generador el Bosque de El Agüil para, de esta manera, potenciar sus cualidades naturales para contrarrestar el desarrollo descontrolado de la ciudad y suplir sus necesidades de espacio público mediante la implementación de espacios con cualidades similares.

M 21 REVISTA M VOL. 10 No.1. ENERO-JUNIO 2013 • FACULTAD DE ARQUITECTURA • UNIVERSIDAD SANTO TOMÁS COLOMBIA 


\section{MENOSCABO DEL VERDE PERIURBANO EN AGUACHICA}

La carrera del hombre hacia los nuevos desarrollos residenciales ha contribuido negativamente a la desaparición de las áreas verdes de margen en las ciudades, espacios con gran potencial para el esparcimiento de la población y la integración con la naturaleza. Todo esto se ha perdido con los años y la "evolución del hombre". En consecuencia, muchas ciudades se ven abatidas por grandes edificios y gigantes avenidas, rogando así por áreas libres destinadas al ocio y al esparcimiento. Este es el caso del casco urbano de Aguachica que cuenta con considerables zonas de expansión urbana con amplios márgenes periurbanos de zonas verdes que han servido durante muchos años como límite entre el suelo urbano y el rural.

Desafortunadamente, con el crecimiento acelerado de la ciudad estas zonas se han visto afectadas por una actividad constructiva abusiva o poco planificada que pretende "devorarlas" y reducirlas hasta el punto de llegar al borde de la desaparición. Entre las debilidades sobresale la ausencia de zonas verdes y espacios destinados al ocio o al esparcimiento de la ciudadanía, problemática verificable al contrastar la realidad de la ciudad con estudios llevados adelante por organizaciones internacionales sobre el espacio público óptimo deseable por habitante en cada ciudad. Así bien, a partir del analisis de investigaciones hechas por la Organización Mundial de la Salud (OMS) se identifica un estándar mínimo de $10 \mathrm{~m}^{2}$ por habitante contra un estándar óptimo de $15 \mathrm{~m}^{2}$ por habitante'.

Tabla I. Confrontación de la disponibilidad de zonas verdes por habitante en Aguachica con otras ciudades.

\begin{tabular}{|c|c|}
\hline CIUDAD & M2 POR HABITANTE \\
\hline Curitiba & 52 \\
\hline Ámsterdam & 27,5 \\
\hline New York & 23,1 \\
\hline Singapur & 17 \\
\hline OMS Óptimo & 15 \\
\hline Seúl & 14,7 \\
\hline Madrid & 14 \\
\hline OMS Mínimo & 10 \\
\hline Barcelona & 5,6 \\
\hline Bogotá D.C & 4,9 \\
\hline Valledupar & 4 \\
\hline Bucaramanga & 4 \\
\hline Aguachica & 1,55 \\
\hline
\end{tabular}

Fuente: Elaboración de los autores con base en indicadores suministrados por la OMS.

Estos indicadores, aplicados a un gran número de ciudades en el mundo y comparados con las actuales condiciones de la ciudad de Aguachica, en términos de espacio publico, permiten determinar a priori la situación existente e iniciar a intuir una problemática común a todo el casco urbano: el déficit de zonas verdes (ver Tabla I).En síntesis, Aguachica se ve agobiada por una serie de problemas emergentes del territorio que van en detrimento del medio ambiente $y$, por consiguiente, afectan directamente a la sociedad. Es evidente la ausencia de concientización en la ciudadanía pero también es notable el escaso

I Organización Mundial de la salud. Indicadores de verde urbano por habitante en el planeta. http://www.who.int/es/, [consultado en 21 de marzo de 20I2] 
apoyo de los organismos y estamentos de gestión, los cuales demuestran un interés casi nulo por estas zonas: no hay evidencia de inversiones ni de mecanismos de protección para estos espacios tan vitales para el desarrollo de la sostenibilidad de la ciudad. Por tales razones, en la investigación se toma como estudio de caso piloto el Bosque de El Agüil, ejemplo claro de la problemática enfrentada: un parque periurbano que cuenta con notables atributos topográficos y naturales, pero que con el paso del tiempo y el auge de la construcción pasó de ser un terreno de 72 hectáreas, a 7 hectáreas (menos del 10\% de lo que era antes). Este espacio natural, además de brindarle al municipio de Aguachica un pulmón verde es un espacio con múltiples cualidades tanto para el esparcimiento, la diversión sana, y la integración social y con la naturaleza. En fin, esta investigación se propone fundamentar la consolidación del Bosque El Agüil como polo inicial para la articulación y desarrollo de un corredor ecológico que rodee el casco urbano de Aguachica y de esta forma le proporcione una serie de focos ecológicos y turísticos tanto para la ciudad como para la región y el Departamento del Cesar.

\section{MÁRGENES PERIURBANOS EN EL MUNICIPIO DE AGUACHICA}

La situación de los márgenes urbanos de Aguachica está directamente ligada a la conformación del trazado urbano de la ciudad, sustancialmente marcado por manzanas regulares y ordenadas a partir de la Calle 5, principal eje articulador de la ciudad que va de oriente a occidente y la cual conecta directamente con la Vía Interdepartamental del Caribe. A partir de ésta espina dorsal, se desarrolla la mayor parte de actividad comercial de la ciudad y además se empieza a expandir irregularmente la ciudad en todas las direcciones, esfumándose el comercio con el uso residencial, caracterizado por viviendas unifamiliares, en su mayoría de uno o dos pisos. A esto se suman los equipamientos institucionales y las escasas zonas dedicadas al verde urbano (ver Figura 2).
Figura 2. Usos del suelo urbano Fuente: Elaboración de los autores

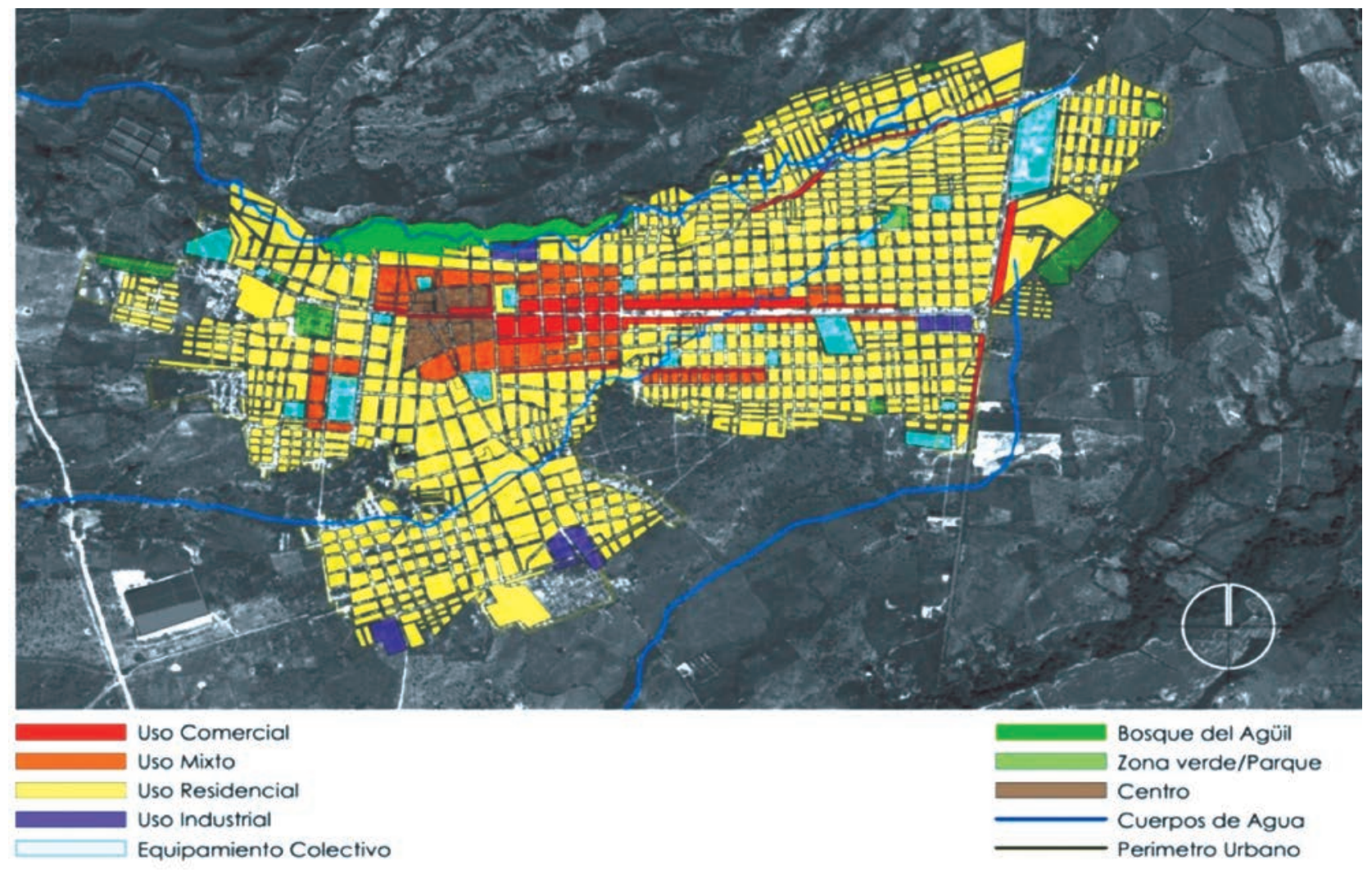

M 23 REVISTA M VOL. 10 No.1. ENERO-JUNIO 2013 • FACULTAD DE ARQUITECTURA • UNIVERSIDAD SANTO TOMÁS COLOMBIA 
Más allá del trazado urbano están los márgenes de la ciudad de Aguachica, afectados y/o determinados por características físicas impuestas por la topografía, la cual marca cierta regularidad en los costados oriental, occidental y sur pero definitivamente muy cambiante al norte, zona en la cual se alcanza una altitud máxima que ronda los $215 \mathrm{msnm}$, donde se localiza un suelo más propicio para el crecimiento de vegetación y la formación de bosques y hábitats para las especies animales. La Figura 3 permite vislumbrar el análisis del margen norte, estudio aplicado a todas las áreas periurbanas de la ciudad. El verde oscuro evidencia las zonas boscosas con alta arborización mientras las áreas en marrón muestran los terrenos dedicados a una incipiente actividad agrícola, agresiva con el suelo y poco planificada.

Figura 3. Caracterización del margen norte del casco urbano de Aguachica. Fuente: Elaboración de los autores.
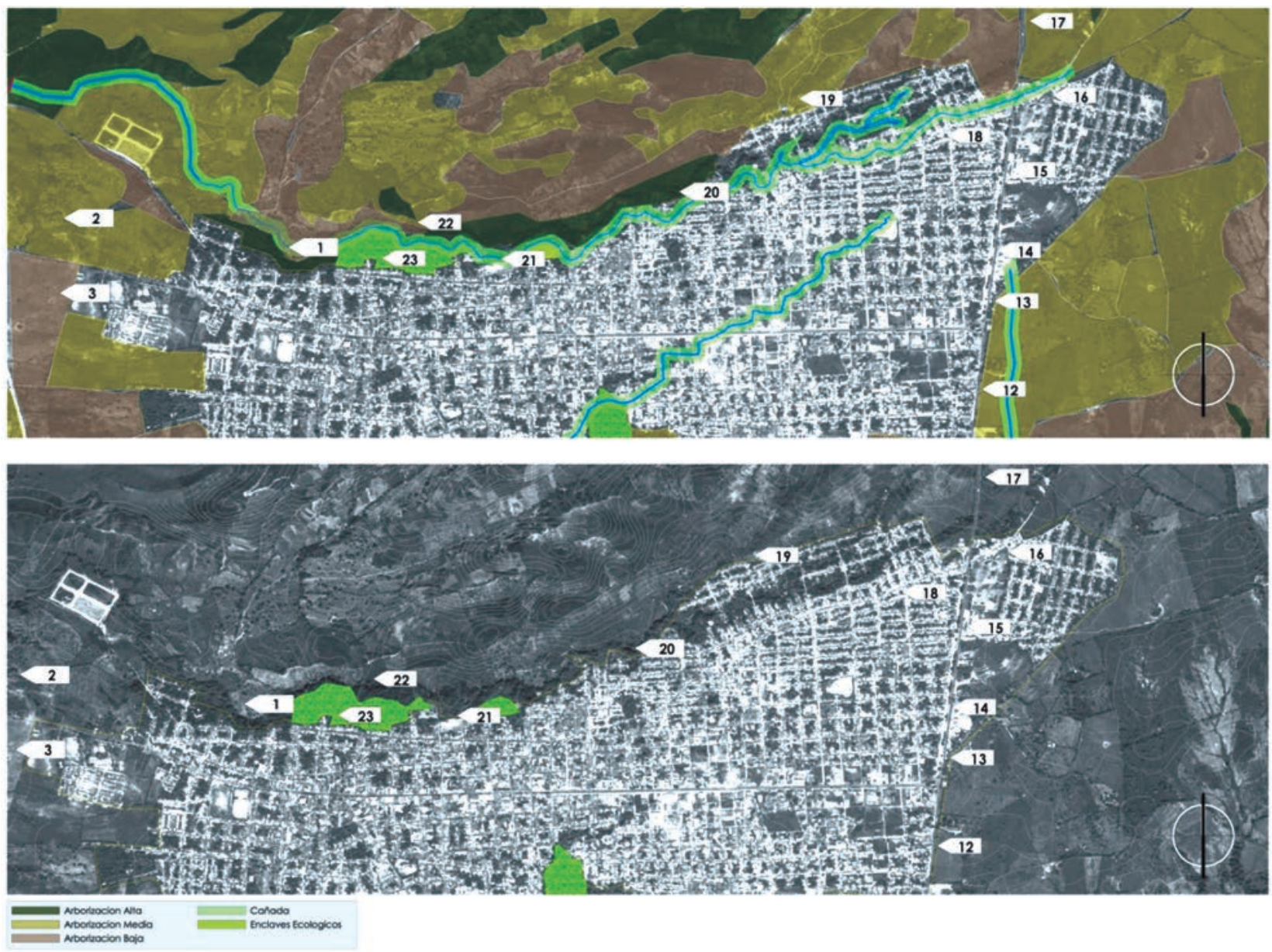

Específicamente, la zona norte, está caracterizada por el gran espacio boscoso que de forma axial demarca la frontera entre la urbe y las actividades agropecuarias en zonas rurales, el denominado Bosque de El Agüil, una joya natural de 7 hectáreas que se localiza al norte del municipio. Esta zona es un claro ejemplo de lo que sucede en el territorio periurbano de Aguachica, se ha deteriorado a causa de los malos manejos y en este momento sus habitantes tienen problemas de salud, de infraestructura, de seguridad, entre otros (ver Figura 4). 


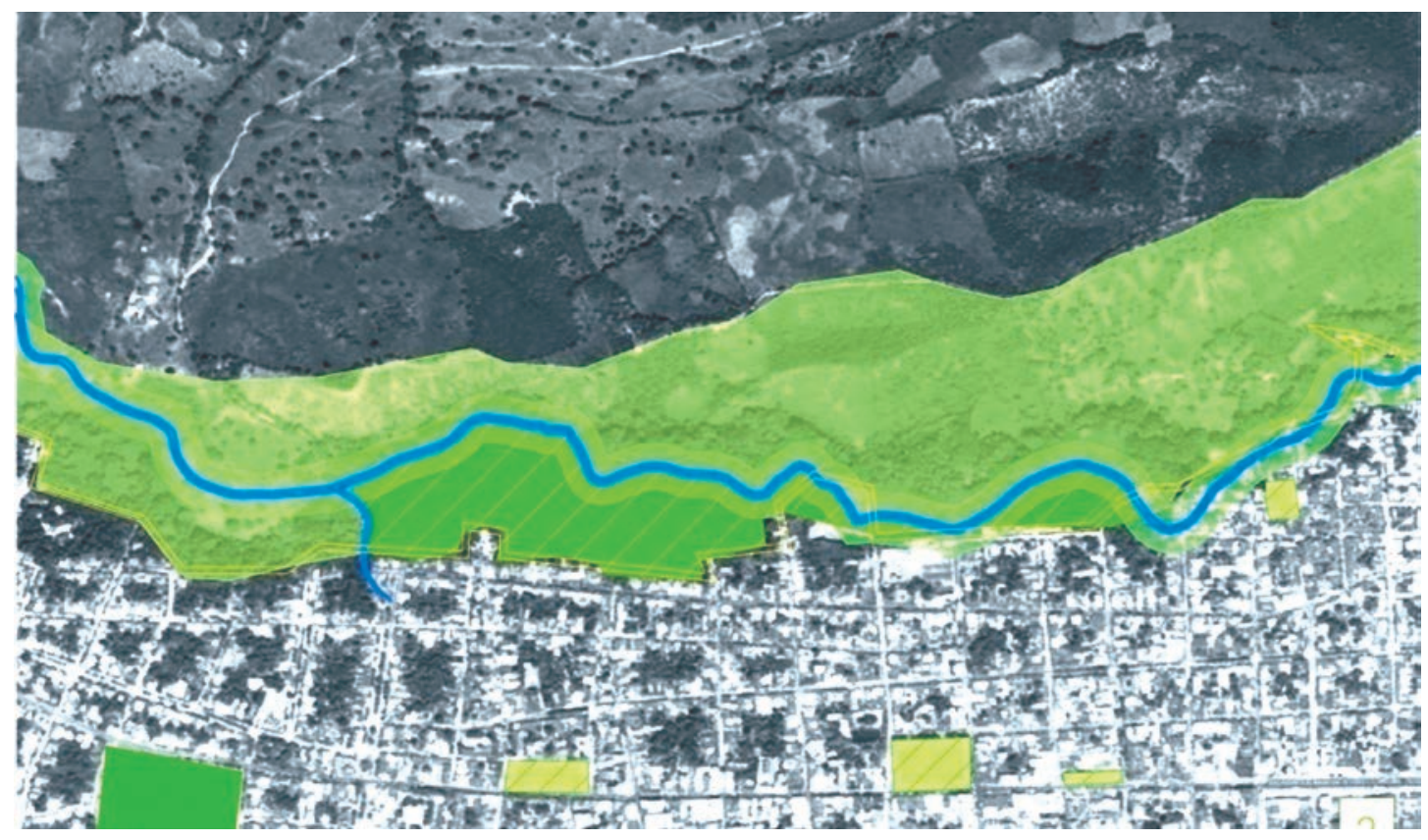

En lo que corresponde a la zona sur se puede determinar áreas de expansión altamente demarcadas, como también espacios invadidos por vivienda informal que afectan el paisaje periurbano. Por estos motivos los espacios de borde urbano empiezan a mermar, debido a la apropiación de terrenos por parte de la población de manera ilegal, que están destinados para otros usos, pero no hay respeto por las leyes. La zona oriental tiene como único y mayor impacto la Troncal del Caribe, vía que conecta el interior del país con la costa Caribe que se convierte en un margen y condiciona el crecimiento del municipio, la mayoría de los asentamientos humanos están ubicados sobre el costado occidental con respecto a la calzada.

Las actividades económicas realizadas en esta zona están relacionadas con vehículos, transportes, hoteles, restaurantes y demás. El único espacio de proyección para vivienda está ubicado en el sector sur de esta zona, esta decisión se tomó con el ánimo de legalizar las viviendas informales que ya estaban asentadas en este lugar. Sobre este margen se encuentra la mayor problemática en cuanto a invasión y apropiación de zonas boscosas, protección de las micro cuencas del municipio y más específicamente sobre el caño El Cristo. Se esperaba un plan de reubicación a raíz de la ampliación de la troncal, pero hasta el momento no se ha desarrollado.

Por último, la zona occidental cuenta con fincas de producción agropecuaria dentro de su margen, pero se ha visto altamente afectada por el desarrollo informal de la ciudad y se encuentran muchas viviendas $y$ tugurios que generan barrios ilegales $y$ por su alto grado de segregación, pareciesen conformar parte de otro municipio. Esta situación es una cadena de problemas que va a afectar, poco a poco, a la ciudad ya que no es sólo un sector el perjudicado, es toda la margen periurbana; es incesante el crecimiento de las masas hacia las áreas libres con que cuenta el municipio en la periferia e insaciable su necesidad por construir y apropiarse de terrenos que no les pertenecen. 


\section{PROBLEMÁTICAS Y POTENCIALIDADES DE LOS MÁRGENES PERIURBANOS DE AGUACHICA}

A partir de la lectura del territorio y el diagnóstico de los márgenes de la ciudad se vislumbraron algunas áreas de importancia ecosistémica que se localizan en el norte, sur oeste y sur del municipio. Estas zonas son el Bosque de El Agüil, el Bosque la Libertad y el Bosque el Potosí, todas de gran valor por poseer los elementos necesarios para pensar a una inminente preservación y rescate de la biodiversidad allí presente que se ha visto altamente afectada por la falta de conciencia social y respeto por el medio ambiente.

Así bien, estos enclaves pueden constituirse como núcleos verdes que pueden ser entrelazados para consolidar paulatinamente un corredor ecológico periurbano. La viabilidad de las conexiones a partir de las visitas de campo permitió establecer las determinantes que afectan las rutas más viables en su planteamiento. La Figura 5 evidencia las posibles conexiones entre los enclaves ecológicos y su grado de viabilidad: la línea punteada en verde oscuro marca los senderos más factibles y la naranja la más inviable o con mayor dificultad de conexión.

Figura 5. Enclaves ecológicos y zonas de conflicto. Fuente: Elaborado por los autores.

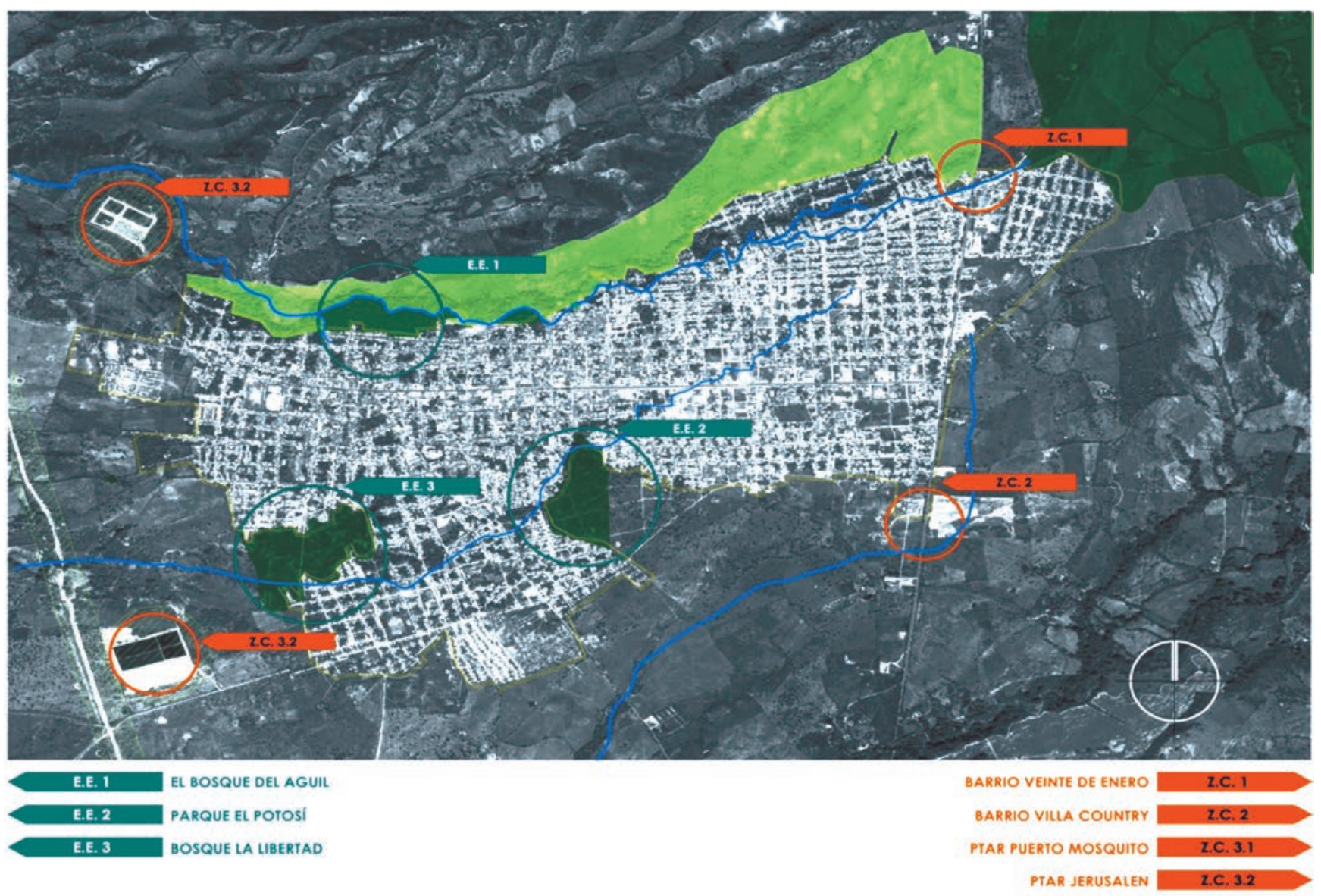

Del diagnóstico realizado salen a luz otras áreas con conflicto en los usos de la tierra, y por consiguiente, afectadas por una fuerte problemática ambiental. Se trata de terrenos donde se invaden las franjas de protección de los cuerpos de agua, se violentan 
los enclaves ecológicos y se compromete la identidad ambiental del municipio. Sin duda, un problema que atenta contra el paisaje del territorio del municipio de Aguachica que aún cuenta con algunas fortalezas que ayudarían a una potencial integración de las zonas verdes, naturales y creadas por el hombre, las cuales simultáneamente proporcionarían un lugar atractivo para la recreación y el deporte, contemplación y ambientalismo para otorgarle reconocimiento nacional e internacional en campos como la ecología, arquitectura y urbanismo. Sin embargo, estas fortalezas se ven opacadas por la amenaza constante de la desaparición de las áreas de protección ambiental y espacios verdes de uso público, producto de las debilidades no tratadas por las administraciones y desatendidas por la población, aumentado de manera exponencial el déficit de zonas verdes, problema que para este caso particular la administración pública no soluciona y, por el contrario, contribuye a agudizarlo al destinar ejidos para nuevos desarrollos o simplemente ignorar las secuelas de aspectos negativos como los altos índices de invasión o la aparición de construcciones con afectaciones legales que son actualmente usadas para otros fines como usos de comercio, vivienda informal y problemas no resueltos por las entidades gubernamentales $y$ tolerados por la sociedad.

En síntesis, un buen número de problemas emergentes identificados y analizados a través de la investigación con el método de causa y efecto permitió visualizar las debilidades, amenazas y otros. Se trata de factores negativos que inciden en esta problemática, la mayoría concernientes al verde urbano, zonas de protección y/o enclaves ecológicos afectados por altos índices de contaminación, desinterés de la población, incompatibilidades en los usos del suelo, falta de planificación y gestión de las administraciones públicas y entidades ambientales.

Los aspectos negativos condensados en la matriz están divididos en dos ámbitos, los fenómenos exógenos o externos y los endógenos o internos, acciones puntuales que impiden el buen estado y funcionamiento de las áreas verdes, además de la interacción con la población y el territorio o entorno inmediato en el que se encuentran. Las estrategias barajadas a partir de la identificación de los factores internos o externos de manera positiva y negativa hacen parte de la relación entre cada una de ellas, que serán vitales para la concretización de los lineamientos estratégicos que articulen un corredor ecológico donde el bosque de El Agüil tendrá un rol protagónico.

\section{ESTUDIOS DE CASO (BESTPRACTICES) COMO BASE DE LA PLANIFICACIÓN DE LAS ÁREAS VERDES PERIURBANAS EN AGUACHICA}

En esta fase de la investigación se observaron, analizaron y determinaron las variantes determinantes de un corredor ecológico, tomado como principio el análisis de cuatro casos internacionales con el fin de encontrar elementos de juicio y bases proyectuales para el desarrollo de un proyecto que permita salvaguardar y reactivar el verde periurbano del municipio de Aguachica. La investigación dirige entonces su mirada hacia la ciudad de Milán (Italia) donde se ubican dos experiencias exitosas relacionadas con el verde periurbano con una fuerte presión por la ciudad compacta. El primero es el Parco Nord Milano (Parque Norte de Milán), un gran parque metropolitano ubicado en la periferia norte de Milán, clasificado como parque regional pues se extiende entre las ciudades de Milán, Bresso, Milanino Cusano, Cormano, Cinisello Balsamo y Sesto San Giovanni. El Parque cuenta actualmente con cerca de 620 hectáreas de tierra que se conservan en las zonas boscosas, praderas, hileras de arbustos, setos y lugares de pequeños estanques.

M 27 REVISTA M VOL. 10 No.1. ENERO-JUNIO 2013 • FACULTAD DE ARQUITECTURA • UNIVERSIDAD SANTO TOMÁS COLOMBIA 
Este proyecto es un ejemplo claro de lo que se puede realizar cuando los entes gubernamentales toman una propuesta con claros enfoques que propenden por un desarrollo urbano sostenible y se enfocan en cumplirla. Cabe anotar que aunque este parque no es considerado como una reserva natural, no obstante sus amplias zonas verdes, es catalogado como un parque regional pues involucra varios municipios que han cedido su gestión a un ente único, denominado Parco Nord Milano, porta estandarte de ideales de lo que pareciese una sociedad única y que contribuye al avance urbanístico de la provincia. Este desarrollo de unos intereses comunes a nivel provincial en Milán, se refleja aún más con el caso del Parco Agricolo Sud Milano (Parque Agrícola del Sur de Milán). Abarca 61 municipios de todo el sector sur de la Provincia de Milán, con 47.000 hectáreas dentro de sus territorios. La idea de la implementación de este parque surge en 1993 con el Plan Territorial de Coordinación del Parque, un instrumento de planificación guía para el desarrollo del mismo.

Este estudio de caso es de particular interés para la investigación por el modelo de conexión de amplios campos de actividades agrícolas que se entretejen con el tejido urbano de los diferentes municipios, modelo que se puede evocar cuando se traen sobre la mesa las zonas de actividades de cultivos y pastoreo que en Aguachica empiezan a gravitar alrededor de la malla urbana y que invitan al planificador a preservar la conexión entre medio ambiente urbano y la agricultura periurbana, así como el fomento del desarrollo comercial y turístico del municipio. Aguachica se ha caracterizado a través de los años por el desarrollo del sector agrícola y agropecuario, con producciones de arroz y labores dedicadas al ganado que son reconocidas a nivel nacional, tanto así que el municipio cuenta con unos de los mejores y más modernos frigoríficos en Latinoamérica.

Sucesivamente, se identifica un proyecto de características interesantes y que demuestra poseer elementos análogos al territorio de Aguachica. Se trata del Anillo Verde Vitoria Gasteiz ubicado en el País Vasco, España. Vitoria Gasteiz, capital de la provincia de Álava, forma parte de la Comunidad Autónoma del País Vasco y es una ciudad de tamaño medio con aproximadamente 220.000 habitantes. Su casco urbano compacto, con áreas residenciales e industriales bien delimitadas pero que ejercen una fuerte presión sobre los márgenes de la ciudad y los enclaves y áreas verdes fragmentadas allí presentes. Por tanto, el anillo es el resultado de un "ambicioso plan de restauración y recuperación ambiental de la periferia de la ciudad que persigue fundamentalmente recuperar el valor ecológico y social de este espacio a través de la creación de un continuo natural alrededor de la ciudad articulado por diversos enclaves de alto valor ecológico y paisajístico", objetivo del Ayuntamiento de Vittoria Gasteiz que bien podría trasladarse o ser adoptado por la Alcaldía de Aguachica.

Finalmente, se trae a colación el anillo verde vertebrador del sistema de espacios libres, situado en la ciudad Zaragoza, España. Este anillo verde se concibe por el Ayuntamiento de Zaragoza "no como algo cerrado en sí mismo, sino como una red capaz de articular los distintos espacios verdes de la ciudad, y con la vocación de desarrollar sub-anillos y ramificaciones". En efecto, una estrategia que se basa en el díseño de "sub anillos" que se insertan en la estructura del anillo verde principal capaz de articular los grandes sistemas verdes fluviales y diversos espacios verdes de ese entorno, integrando además los espacios periurbanos con los urbanos.

Los ejes principales para el desarrollo del anillo parten de las cuencas hidrográficas que suplen a la ciudad como el río Ebro, y el río Gallego. En el análisis sobre el cinturón verde de Zaragoza se resalta la particularización sobre la zona norte del cinturón, fundamentados en la existencia de dos cuencas hídricas que marcan las pautas del proyecto, muy similar 
a los nacimientos de agua que atraviesan el municipio de Aguachica y proporcionan los fundamentos para el desarrollo del corredor ecológico.

\section{HACIA LA ARTICULACIÓN DEL BOSQUE DE EL AGÜIL EN UN CORREDOR ECOLÓGICO PERIURBANO}

Con base en las situaciones y experiencias identificadas en los anteriores procesos de la investigación se identifican algunas preguntas específicas, latentes desde el momento en que se formularon las hipótesis, pero que ahora son evidentemente explícitas: ¿Cómo implementar un proceso adecuado dirigido a la consolidación de un corredor ecológico periurbano para Aguachica en el cual el Bosque de El Agüil juegue un papel preponderante? Esta pregunta ofrece mucho que pensar y plantea más interrogantes sobre el futuro de este proceso: se requiere de un plan específico para implementar un corredor ecológico, 0 ¿Es más viable encontrarle un espacio al corredor ecológico en los planes municipales con políticas periurbanas? ¿Se requiere apoyar la producción de bienes y servicios al interior del corredor, destinados a la comunidad de Aguachica? o ies mejor pensar en un apoyo a la diversificación de las actividades actualmente existentes en los territorios periurbanos a cambio de una oferta de "servicios semi-rurales" a la ciudad?

En síntesis, una serie de interrogantes a los cuales se puede dar respuesta después del proceso de investigación, basado en una cuidadosa lectura del territorio y una praxis fundamental para el proceso de planificación: el acercamiento a la población. De las encuestas realizadas se pudo conocer la opinión de un alto porcentaje de residentes de la periferia y ciudadanos que viven en el casco urbano, especialmente cerca de las zonas verdes afectadas ambientalmente. Las preguntas se enfocaron a conocer el concepto de la población sobre la actualidad del municipio, la calidad de sus espacios verdes, sus necesidades y sus fortalezas. Se abarcó 4 grupos etéreos: de 10 a 20 años, de 20 a 40, de 40 a 60 y de 60 en adelante. La idea era abarcar todos los rangos de edades que tuvieran la conciencia necesaria para reconocer y resaltar los problemas que padece actualmente el municipio, y de esta manera justificar nuestra propuesta a sabiendas de que el problema es notorio para todos.

Los resultados obtenidos fueron: el $72 \%$ de la población entre 10 y 20 años considera que Aguachica no cuenta con las zonas verdes necesarias, y el $92 \%$ de los mismos considera que debería contar con más parques en su periferia. También cabe resaltar producto de las encuestas, que el $46 \%$ de la población de 20 a 40 años considera agradable transitar o caminar por el bosque de El Agüil, lo cual indica que es necesario fomentar este tipo de actividades dándole la importancia y el manejo adecuado al Bosque para que este porcentaje de población aumente. Nos adentramos en el mundo de lo probable, pero siempre pensando en hacer suposiciones fiables que lleven a investigar el futuro de la campaña periurbana en los centros urbanos de Colombia con características similares al de Aguachica.

Básicamente, se trata de desarrollar algunas consideraciones de diseño en un proceso que intenta adaptar, e incluso mezclar, las mejores metodologías identificadas a largo de la investigación con la realidad territorial de Aguachica, todo con el objetivo de sentar las bases para un mejoramiento concreto y preservación de las áreas periurbanas de la ciudad e inclusive de los centros urbanos de Colombia. Para ello, esta parte conclusiva de la investigación se desarrolla a través de cuatro supuestos principales que resaltan algunas cuestiones clave para el posible desarrollo de métodos de intervención en las áreas periurbanas del territorio estudiado. El primero parte de la consolidación de un Corredor Ecológico Periurbano para Aguachica que desde este momento será referenciado con la sigla CEPA.

M 29 REVISTA M VOL. 10 No.1. ENERO-JUNIO 2013 • FACULTAD DE ARQUITECTURA • UNIVERSIDAD SANTO TOMÁS COLOMBIA 


\section{Articulación del CEPA desde el bosque de El Agüil como punto de partida}

Este lineamiento demanda como punto de partida la individuación de un área ambientalmente frágil, a fin de reconocerla como eventual polo generador de desarrollo ambiental, en este caso el Bosque de El Agüil, sección del territorio periurbano de Aguachica en el cual intervenciones de carácter antrópico han desencadenado alteraciones del ecosistema que pueden ser irreversibles. Se pasa entonces a buscar una percepción extensa del territorio, para reconocer las áreas adyacentes inmediatas y proceder a una amplia escala de análisis territorial. (ver Figura 6 ).

Sin duda, las características físicas del Bosque de El Agüil, sus fortalezas y también sus puntos débiles, lo invisten como el escenario piloto del CEPA, a su vez, obligan a encontrar respuestas oportunas siempre pensando en el mantenimiento de una conexión consolidada entre la ciudad y el área rural a través de un área boscosa, con innumerable biodiversidad, fuertemente relacionada con el territorio urbano y al servicio de la ciudadanía, teniendo en cuenta que este polo será el inicio de un corredor que conectara diferentes enclaves ecológicos presentes en Aguachica los cuales repercutirán en términos de calidad de vida, o sea, un nuevo verde urbano tan importante como otras necesidades: transporte, vivienda y demás.

Figura 6. El Bosque del Agüil como punto de partida del CEPA. Fuente: Elaboración de los autores.

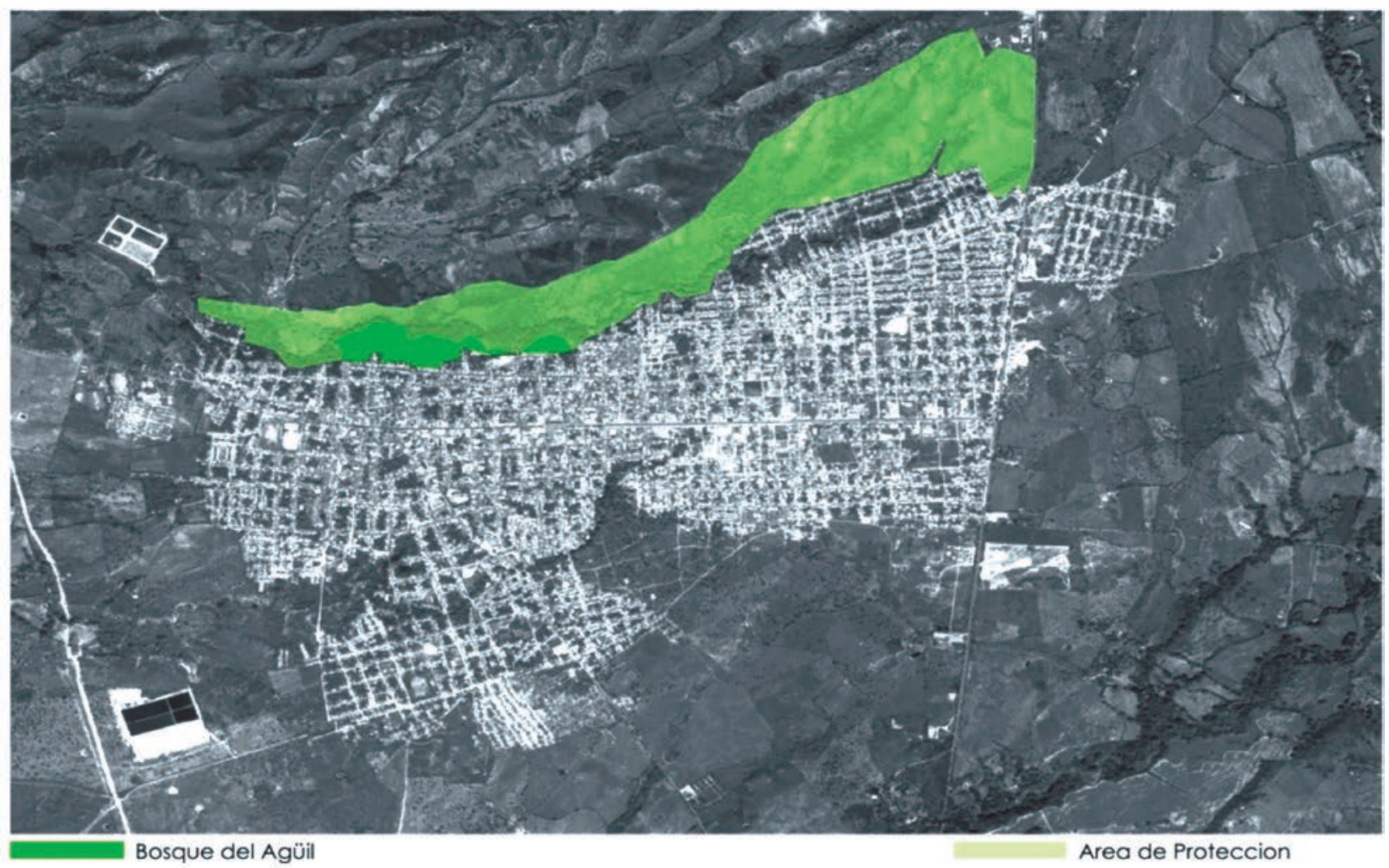




\section{Articulación de enclaves ecológicos (EE), zonas de conflicto (ZC) y primera conformación del Corredor Ecológico Periurbano de Aguachica (CEPA)}

Se toma como fundamento inicial los resultados obtenidos en la lectura del Territorio y posteriormente en el apartado dedicado al análisis y diagnóstico, con el fin de determinar las características primordiales del territorio periurbano, sus debilidades y potencialidades. Es, entonces, cuando se identifican otras zonas periurbanas con características no necesariamente idénticas al Bosque de El Agüil pero si con valores ambientales susceptibles de ser protegidos o revitalizados. Estas zonas asumirán el calificativo de Enclaves Ecológicos (EE) y Zonas de Conflicto (ZC), poseedores de una serie de particularidades que las pueden constituir en polos periurbanos de desarrollo ambiental. Estas son el Bosque de El Agüil, el Bosque de la Libertad, el Parque el Potosí, acogidas en la categoría de Enclaves Ecológi$\cos (\mathrm{EE})$ y los barrios Veinte de Enero y Villa Country así como las Plantas de tratamiento Jerusalem y Puerto Mosquito que se engloban en las Zonas de Conflicto (ZC) las cuales se registran en la Figura 5.

Figura 7. Zonas específicas: enclaves ecológicos y zonas de conflicto. Fuente: Elaborado por los autores.

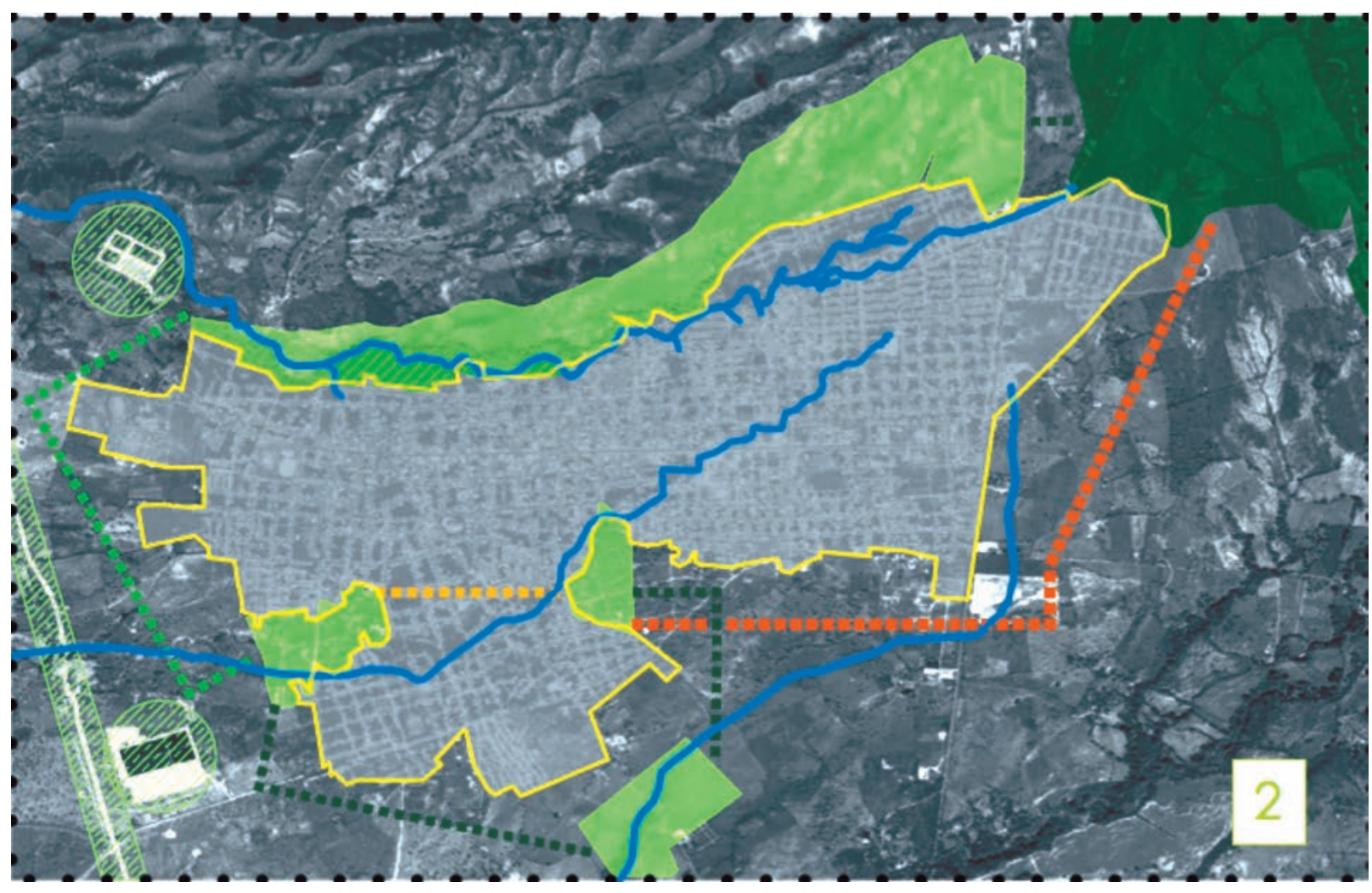

De esta manera, se establecen una serie de nodos que se integrarán eventualmente a un corredor verde mediante tratamientos adecuados para tal fin igualmente. Las cualidades y potencialidades de los terrenos involucrados deberán propiciar la redefinición, consolidación o adecuación de los usos allí presentes y las conexiones alrededor del casco urbano. Es en este momento que se vislumbra el primer esbozo del Corredor Ecológico Periurbano (CEP), sustentado en precedentes análisis para así delinear, una eventual, pero viable 
franja conectiva entre los componentes de las zonas específicas que permitirá un oportuno espacio de transición entre la ciudad y el territorio rural. (ver Figura 8)

Figura 8. Primera conformación del corredor ecológico periurbano de Aguachica (CEPA) Fuente: Elaborado por los autores

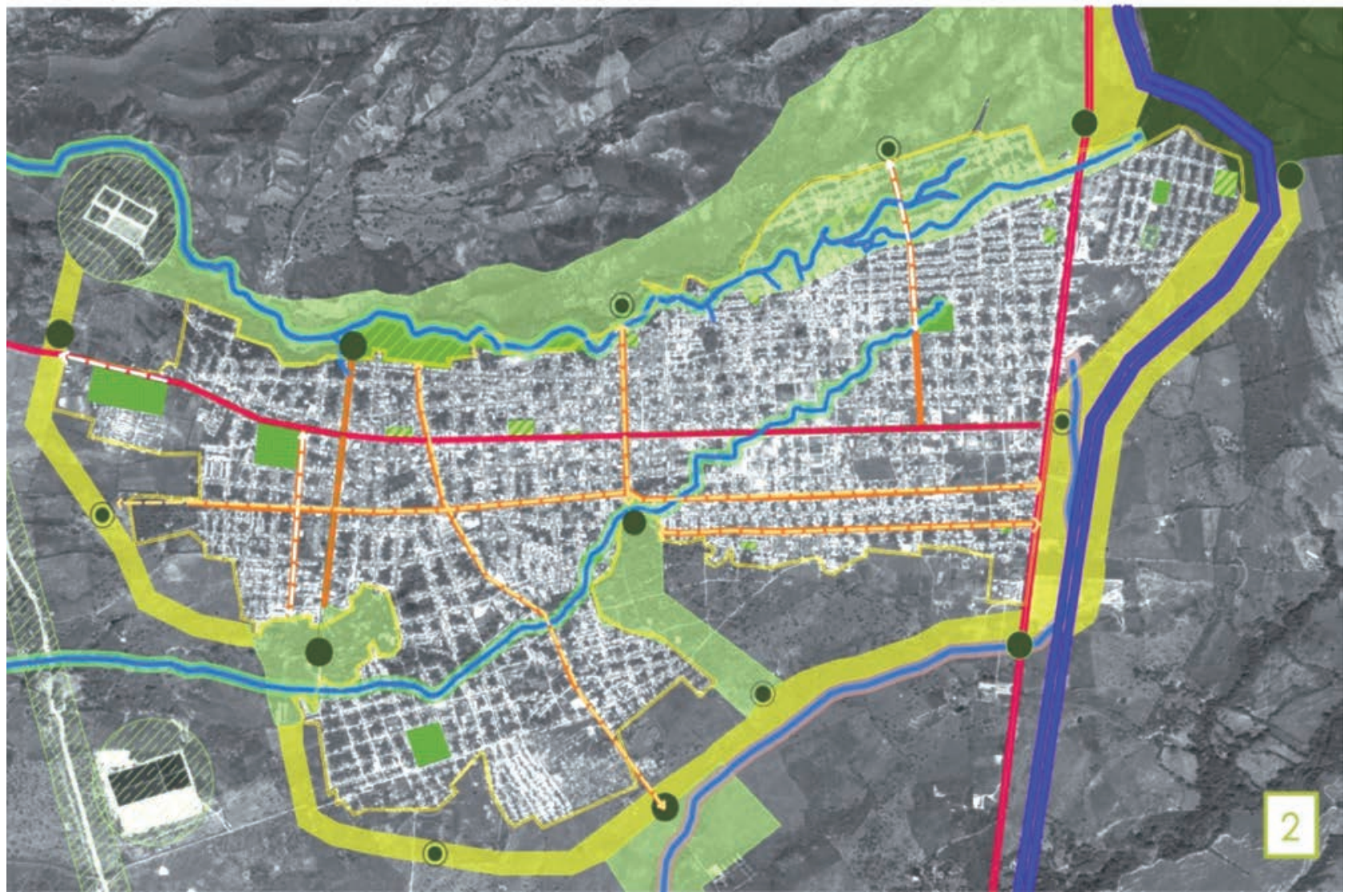

\section{Particularización de las intervenciones en los enclaves y el corredor ecológico}

El objetivo de este lineamiento es sentar las bases para la definición de eventuales estrategias o actuaciones específicas que a su vez deberán ser aplicadas según la normativa que tendrán a bien establecer los planificadores y los legisladores que velarán por la aplicación concreta de las medidas previstas. Este aspecto será ampliado en el lineamiento referido al manejo del territorio periurbano desde la gestión y la interinstitucionalidad. Se sugiere a través de la fabricación de una malla ortogonal, que divida el territorio de acuerdo a su ubicación geográfica por secciones o cuadrantes que permitan la caracterización de cada una de estas zonas. Cada cuadrante o sección, individualiza las características morfológicas y territoriales de manera particular para a su vez ser tuteladas o intervenidas a través de instrumentos de planificación que permitan establecer normativas o intervenciones a nivel de detalle. (Ver Figura 9).

Se trata de delinear los escenarios donde se especificarán en detalle usos permitidos, límites a la actividad constructiva, prohibiciones, expropiaciones, traslados y otras actividades dirigidas a la protección del territorio periurbano. Esta gama de acciones, actividades o estrategias son simplemente la respuesta lógica a la declaración del espacio periurbano como bien de interés público inherente a la aprobación del Corredor Ecológico 
Periurbano. Basados en estos dictámenes se podría entrar en una dimensión más profunda de la particularización que lleva a consideraciones específicas de diversa índole a tener en cuenta para el desarrollo del corredor ecológico, tales como disposiciones puntuales para la protección de la fauna y la flora para las cuales se requiere un trabajo interdisciplinario. Seguidamente, se tienen en cuenta los perfiles externos e internos del corredor ecológico, o sea, el diseño especifico del corredor mediante la utilización de materiales amigables con el medio ambiente y la inclusión de zonas boscosas entrelazadas con los cultivos, la generación de zonas de protección para la biodiversidad, la generación de una barrera natural (setos verdes) para mermar el crecimiento abrupto de la ciudad y estrategias para la protección de los caños presentes en el territorio, con el fin de poder rescatar este recurso hídrico, vital para el desarrollo de la población.

Figura 9. Cuadrantes y Plan Particularizador C-5I. Fuente: Elaborado por los autores.

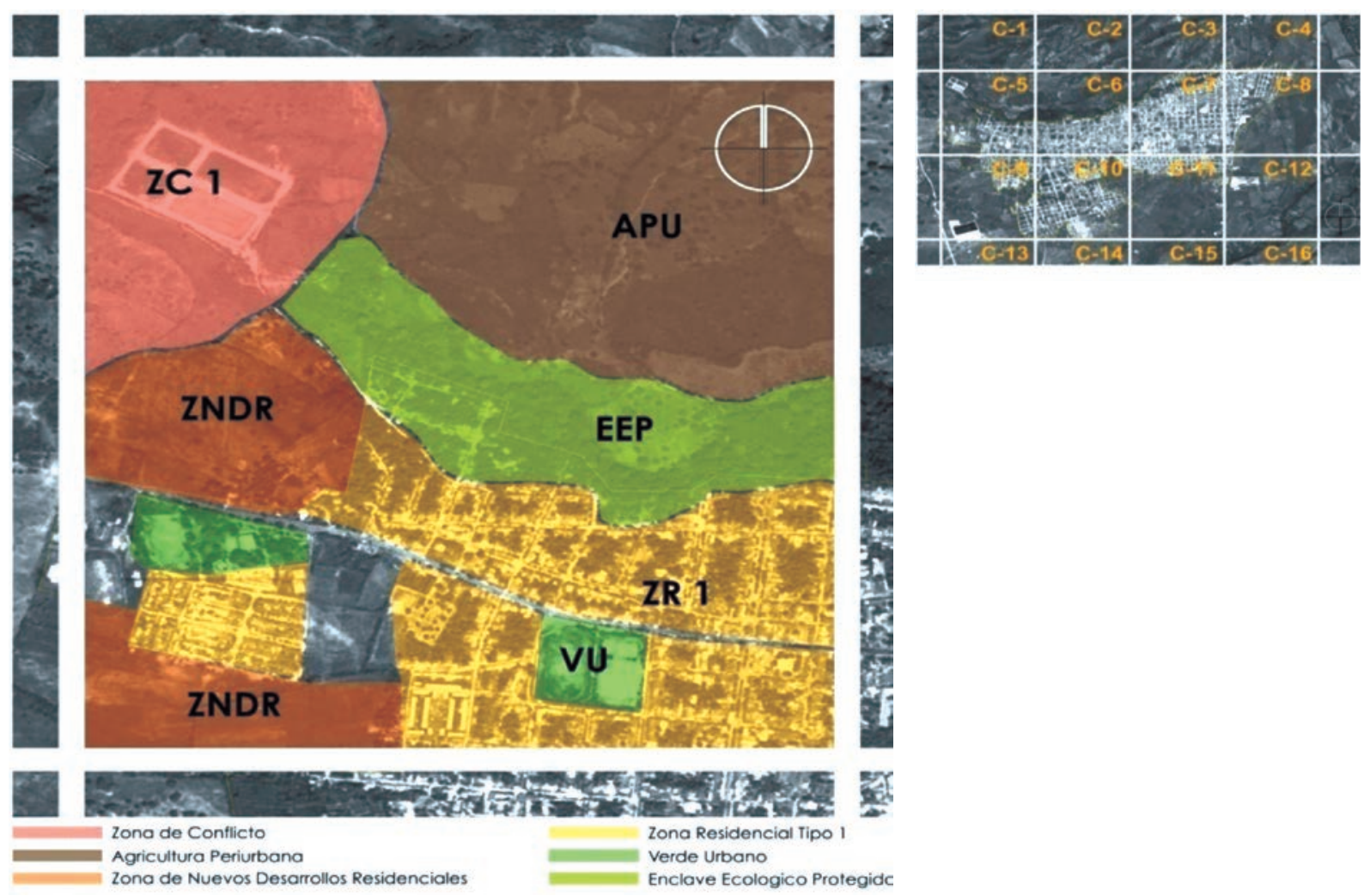

En el caso de las áreas colindantes con el territorio rural de Aguachica, es pertinente la inclusión de un modelo más específico para la protección de éstas, ya que es aquí donde la investigación trae a luz la importancia de la Agricultura Periurbana (AP) ampliamente evidenciada en el caso del Parco Agricolo Sud Milano (PASM). Se tiene en cuenta además la implementación de "estructuras de cruce" como Pasafaunas, Ecoductos y Greenways dentro del CEPA pues es oportuno, por ejemplo, actuar sobre algunos puntos de conflicto identificados sobre las vías. Estas estructuras ofrecen alternativas para la continuidad de la masa forestal viable, funcional y sostenible, de gran éxito en situaciones como la del proyecto Espacio Natural y Reserva de la Biosfera de Doñana (Andalucía, España), también estudiados en la investigación. 


\section{Desde la protección de los enclaves ecológicos hasta la multifuncionalidad}

Se aborda aquí una estrategia dirigida a la inclusión de los enclaves ecológicos en función de la vivencia y relación con los habitantes desde una perspectiva protectora de la biodiversidad y el alto valor paisajístico en el territorio que generan estos espacios por su función estética. A esto se agregan las múltiples funciones que los espacios verdes ofrecen al territorio y en especial a los habitantes, en campos como la producción, la salud, la educación ambiental y cultural, el ambientalismo, la protección de áreas sensibles y la integración social-recreativa. Relacionado el proyecto con actividades fuera de su función primaria, estudiadas en proyectos similares como el Parco Nord Milano, referenciado en Confrontación Normativa y Tipológica, se puede sugerir:

- La recreación en áreas cercanas a equipamientos deportivos, en el caso de las áreas de borde contiguas al Polideportivo y el estadio Francisco Ramos Pereira.

- La posible implementación de áreas destinadas a la expansión urbana dentro del corredor ecológico, que compacten el desarrollo del casco urbano hacia el futuro.

- El uso del suelo para la producción y turismo agrícola puede ser eventualmente aplicable a las áreas anexas al CEPA de manera externa con respecto al municipio, especialmente en las proximidades al barrio IDEMA y la vía al corregimiento de Puerto Mosquito.

\section{Manejo del territorio periurbano desde la gestión y la interinstitucionalidad}

La protección y disfrute de los enclaves ecológicos de Aguachica, establecida como el resultado del manejo u ordenamiento del territorio que comprende las áreas de borde urbano, así como la transición a los espacios rurales y todas las dinámicas que confluyen en el ámbito supramunicipal, dependerá de la inclusión de políticas y estrategias que lleven a cabo acciones que generen un uso responsable pero productivo del suelo. De esta manera se busca erradicar del territorio las actividades perjudiciales para las áreas periurbanas que han profundizado las problemáticas del espacio público, manejo ambiental, recreación, normatividad, y contaminación identificadas durante la ejecución de la Lectura del Territorio, posteriormente puntualizadas en el Análisis y Diagnóstico. Estos inducen a la importancia y pertinencia del trabajo articulado de las instituciones con competencia dentro del municipio, a que contribuyan a la conservación, protección y promoción de las áreas verdes, así como la constante actualización de los datos que conciernen al conocimiento, análisis y diagnóstico de los enclaves ecológicos. El manejo y gestión por parte de las entidades municipales de cada división administrativa, estructurada con base en la planificación (técnicas e instrumentos) y gestión (políticas y estrategias) del territorio, permite la posible inclusión de las siguientes estrategias:

- La eventual creación de una entidad de planificación y gestión para las áreas rurales y de borde urbano en los municipios que conforman el Valle del Magdalena, y la posterior presentación de un Plan de manejo u ordenamiento de las áreas rurales a escala supramunicipal (PORS) que vele, proteja y planifique el crecimiento de los municipios, así como la regulación de actividades agropecuarias en áreas rurales. 
- La caracterización y clasificación de los espacios de borde urbano según su valor paisajístico, potencialidades, conflictos y la relación directa con el espacio urbano o rural que posean, como método de planificación del territorio para establecer métodos de intervención homogenizados o particularizados según el caso.

- La Implementación de un Plan de Manejo Ambiental (PAM) dirigido a la protección de las zonas de biodiversidad, pues este instrumento de gestión favorecería a la regulación y control del crecimiento urbano, evitaría la invasión de los enclaves ecológicos y las incompatibilidades en el uso de sus suelos, ya que esto contribuye a la destrucción del ecosistema en el municipio. Es urgente tomar medidas sobre esta problemática que agobia los enclaves ecológicos, afecta sus potencialidades y agrava sus debilidades. A razón de esto se incita a proponer el PAM, que de manera simultánea actuaria como agente propiciador para consolidar la conectividad de los citados enclaves, como estrategia de protección y salvaguarda de los espacios periurbanos y las zonas de alta biodiversidad que colaboran a suplir el déficit de zonas verdes del municipio (Ver Anexo A).

- El proceso investigativo sugiere el óptimo tratamiento de los residuos por parte de la empresa de servicios públicos EMPOAGUACHICA, en coordinación con la administración municipal y demás entidades competentes, para la posible reubicación de las plantas de tratamiento de aguas residuales, identificadas en la Lectura del Territorio, ya que se localizan en sectores demasiado próximos al casco urbano, sobre las zonas Noroccidental y Suroccidental del municipio, influenciando en la calidad de vida de los habitantes de los barrios aledaños. También es pertinente sugerir una mejor disposición y métodos de tratamiento de los residuos sólidos en zonas más alejadas a la cabecera municipal, con el apoyo y colaboración de la comunidad a través del Plan de Gestión Integral de Residuos de Aguachica (PGIRA).

- El corredor ecológico como un potencial espacio de vivencia y protección, respaldado en la formulación de Políticas y Campañas por parte de entidades como CORPOCESAR y el Instituto municipal de recreación y deporte (IMDREC) que actualmente no cumplen un papel protagónico en el impulso del uso controlado de los espacios verdes, a través de los equipamientos planteados para el aprovechamiento y cuidado de los mismos.

- La funcionalidad e integración del corredor ecológico en relación con el territorio y la población deriva de la oportuna y beneficiosa creación de la CORPORACIÓN PARA LA DEFENSA DEL CORREDOR ECOLÓGICO DE AGUACHICA (CDCEA) como organismo protector y articulador del desarrollo armónico de este espacio verde. Tomados como referencia los estudios de caso como el Parco Nord Milano, ParcoAgricolo Sud de Milano y el cinturón verde de Vitoria Gasteiz enunciados en la Confrontación Tipológica, en los que se incorporan organismos para el cuidado, la preservación y bienestar de los mismos, desde la culturización de la población mediante el uso de normas y medidas preventivas que contribuyen a la armónica relación de la sociedad y la naturaleza. Paralelamente la población debe contribuir en las decisiones de CDCEA dentro del proceso participativo y su obligación de defender los intereses del municipio.

- La posible instauración de los instrumentos de gestión para la protección de los enclaves y mejora del paisaje periurbano anteriormente enunciados, esperan concretizarse a través de la legalización de predios incluidos en el corredor ecológico, la reglamentación de las actividades, usos y materiales amigables, coherentes con la función de estos espacios y vigilar el cumplimiento de la normativa por parte 
de las administraciones públicas o entidades privadas encargadas del mantenimiento de CEPA, para promover la conservación, protección y promoción de las áreas con biodiversidad y espacio público.

\section{La gestión participativa para el desarrollo sostenible del CEPA}

La gestión participativa tiene como finalidad la contribución en la toma de decisiones sobre el corredor ecológico por parte de la población local. De manera tal que el desarrollo y el funcionamiento activo del CEPA está directamente relacionado con las decisiones y las interacciones de la población de Aguachica.

Durante todo el proceso de investigación, se pudo contar con la participación activa de la población, un ejemplo claro se refleja en el muestreo poblacional. Como se pudo determinar que el $\mathbf{6 3 \%}$ de la población piensa que la intervención del gobierno sobre los espacios verdes es deficiente, y el $95,57 \%$ está de acuerdo con la propuestas para la intervención de las mismas. Esto permite sugerir que la interacción de la sociedad con el desarrollo del CEPA, sería completamente aprobada y apoyada. Esto propiciaría además la articulación de campañas de turismo al impulsar los atractivos ecológicos del municipio con la finalidad de transformar al municipio de Aguachica en un lugar turístico a nivel nacional, presentándolo como un foco de biodiversidad ecológica, educación, y diversión para todo tipo de personas.

En lo específico, se podrían implementar actividades como excursiones, observación y fotografía de la fauna local, senderismo, ciclo montañismo, agroturismo y trailrunning que a su vez van de la mano con el proceso dirigido a fortalecer la educación ambiental y cultural en pro del respeto y cuidado de la biodiversidad. Esta propuesta implica programar actividades de culturización y enseñanza sobre la protección de las zonas verdes y la biodiversidad local, para que se les brinde el uso adecuado:

- Apoyo a proyectos de investigación y desarrollo de carácter ambiental en niveles académicos.

- Fomentar recorridos por el corredor ecológico con el fin de dar a conocer el entorno inmediato, y de esta manera generar el sentimiento de apropiación.

- Campañas de protección y cuidado ecológico en las escuelas, colegios y universidades locales.

- Pancartas informativas a nivel municipal sobre las cualidades y potencialidades del corredor ecológico como enclave natural.

Finalmente, se identifica como elemento clave para el desarrollo y sostenibilidad del CEPA la vinculación de la empresa privada para la generación de empleo a través del mantenimiento de las zonas verdes, o sea, incluir empresas tales como la Asociación de Ingenieros y Arquitectos (AIA) que se encarga de contribuir a la construcción de paisaje urbano, el CEBU, directamente relacionado con la producción agropecuaria y el desarrollo de las actividades en el ámbito rural y de igual manera, las empresas asociadas a la promoción del turismo como es el caso de VIVETOUR S.A. 


\section{CONCLUSIONES}

Durante el desarrollo de las fases metodológicas que acompañaron el proceso de investigación se identificaron diferentes aspectos que sirvieron como referencia para establecer la viabilidad de un corredor ecológico periurbano en el municipio de Aguachica, susceptible de consolidarse a partir de la conexión de las zonas forestales, áreas de protección ambiental, parques recreativos así como a través de algunas áreas de conflicto con ciertas particularidades. Sin duda alguna, el papel y la participación del Bosque de El Agüil en este proceso fue decisivo por su envestidura como polo articulador y punto de partida para establecer la conectividad de áreas similares a él o con elementos afines en términos de potencialidad para consolidarlas y convertirlas en enclaves ecológicos.

Es así que la investigación detecta estos enclaves como núcleos capaces de propiciar un desarrollo paisajístico, ambiental y territorial en la zona periurbana del municipio, mediante instrumentos que potencien y exploren sus características y cualidades naturales. Así bien, la conexión e integración de las áreas de biodiversidad a través de un corredor verde formaría un ideal espacio de transición e integración entre el espacio rural y lo urbano al conformar un paisaje armónico logrado gracias a estrategias de protección y revitalización de las áreas de margen que bien podría revertir en la sostenibilidad de las zonas forestales, las de protección ambiental y los parques recreacionales.

De alto aporte a los problemas medio ambientales de la periferia sería también la inclusión de espacios conflictivos o problemáticos con el proceso de planificación del espacio periurbano. Paralelamente, el proceso de búsqueda hacia la integración de los enclaves ecológicos que conformarían el potencial corredor ecológico, permitió entrever la viabilidad y el gran impacto positivo que éste podría generar en las dinámicas urbanas de la ciudad de Aguachica. De igual forma, la investigación develó la importancia de establecer una conjunción férrea entre varios elementos, agentes y actores relacionados con el territorio de Aguachica, en especial con las áreas de borde urbano. Aparece además la trascendencia del trabajo ambiental y la reciprocidad de la comunidad hacia estos espacios, partes vitales de un engranaje necesario para el desarrollo del corredor ecológico y la visualización del municipio con una perspectiva de territorio sostenible y productivo.

En términos de sostenibilidad y productividad del uso del suelo, la conformación del corredor ecológico en el territorio de borde urbano requiere, sin duda alguna, de la articulación de oportunos procesos de gestión y participación de las administraciones públicas y la población. Asimismo, el proceso investigativo, sugiere la participación activa de la empresa privada en la conformación y mantenimiento de las zonas de conectividad y enclaves ecológicos. Se trata claramente de una estrategia que requiere del acompañamiento y participación de la población, factor imprescindible para regularizar el desarrollo óptimo de las áreas de expansión urbana y que, a su vez, solventen las necesidades de áreas verdes en Aguachica y del impulso turístico para generar nuevos ingresos económicos en el municipio. Sólo de esta forma, sin duda, podría generar un impacto positivo, viable y sostenible que revertiría en una nueva actitud por parte de la población con relación a los temas ambientales $y$, a su vez, motivar la inclusión de este tipo de proyectos en la agenda de administración pública.

Sin embargo, la investigación y específicamente la verificación de la hipótesis, todas estas referidas implícitamente a lo largo de estas conclusiones, ponen sobre la mesa el grave problema de las escasas técnicas e instrumentos de planificación así como de los planes y políticas de gestión del territorio. Al respecto es clara la inconsistencia en los mecanis- 
mos de control sobre el poder decisional y ejecutivo de la entidades administrativas del municipio así como la negligencia administrativa de los llamados a ser los "operadores del territorio" en el municipio de Aguachica. Se pone aquí en resalto, un problema de fondo que requiere, en cualquier caso, de posteriores estudios de profundización pues es indiscutible que sin una nueva clase dirigente, capacitada y con alto interés por el bien común, estos problemas continuarán agravándose y podrían poner en peligro el desarrollo sostenible del territorio en Aguachica.

\section{REFERENCIAS}

ALCALDÍA DEL MUNICIPIO DE AGUACHICA. (20I0). Plan de Ordenamiento Territorial Municipio de Aguachica. Documento en aprobación. Colombia.

ALCALDÍA DEL MUNICIPIO DE AGUACHICA. (20I2). Plan de Desarrollo Municipal de Aguachica. Colombia.

AYUNTAMIENTO DE VITORIA GASTEIZ. European Green Capital, en:<http://www. vitoria-gasteiz.org/we00I > [consultado en 4 de mayo de 20I2]

Busi, R. (2002). Greenway nella pianificazione urbana e territoriale. Bresica: Sintesieditrice.

CONCIERGE.COM. Parco Nord Milano, en: < http://www.concierge.com/images /italy/ milan/milan_0I3p.jp> [consultado en I 8 de marzo de 20I2]

EL ANILLO VERDE NORTE, Ayuntamiento de Zaragoza, en<http://www.parquedelagua. com/index.php/anillo-verde-de-zaragoza/anillo-verde-de-zaragoza-norte/ $>$ [ consultado el 17 de mayo de 20I2]

EL CORREO.COM. Los seis parques naturales de Vitoria, en: < http://info.elcorreo.com/ vitoria/anillo-verde/> [consultado en 2 I de marzo de 20I2] 
Gómez Orea, D. (2007). Ordenación territorial. Madrid: Ediciones Mundi-prensa, 2007.

Gómez Piñeiro, J. (1987). Análisis geográfico, ordenación del territorio y medio ambiente. Donostia: Ingeba.

LOS CIUDADANOS DE LOS PARQUES. Parco Regionale Nord Milano, en:<http://2. bp.blogspot.com/PUoaU838pl/ Parco_regionaleNordMilano.jpg> [consultado en I3 de julio de 20I2]

Massiris, Á. (2006). Políticas latinoamericanas de ordenamiento territorial: Realidad y Desafíos. Tunja: Universidad Pedagógica y Tecnológica de Colombia.

Mata, R.,Tarroja, A. (2006). El paisaje y la gestión del territorio: Criterios Paisajísticos en la Ordenación del Territorio y el Urbanismo. Barcelona: Diputació Xarxa municipios.

Méndez, A. C. A. (2003). Metodología: Diseño y desarrollo del proceso de investigación. Bogotá: McGrawhill.

MINISTERIO DE AGRICULTURA, ALIMENTACIÓN Y MEDIO AMBIENTE DE ESPAÑA, en:<http://www.magrama.gob.es/es/> [consultado en I5 de mayo de 20I2]

Navarrete, J. F. Territorio: Asentamientos de borde. En: Revista Escala. No. 225. p. I I0

Navarro, A. (20I2). El Bosque de El Agüil, joya natural amenazada. Bogotá: Agencia de Noticias UN, en:<http://www.agenciadenoticias.unal.edu.co $>$ [consultado en 28 de febrero de 2012]

PARKS.IT. Parco Nord Milano, en: <http://www.parks.it/Parco.nord.milano/mapl. jpeg $>$ [consultado en 5 de marzo de 2012]

Zazo, A. El parque agrícola del Sur de Milán: La primera incorporación de un espacio agrícola periurbano al sistema urbano, en: $<$ http://habitat.aq.upm.es/eacc/amilan.html $>$ [consultado en 15 de junio de 20I2]

M 39 REVISTA M VOL. 10 No.1. ENERO-JUNIO 2013 • FACULTAD DE ARQUITECTURA • UNIVERSIDAD SANTO TOMÁS COLOMBIA 